\title{
SOBRE MONSTROS E SERES IMAGINÁRIOS NA OBRA DE MOACYR SCLIAR: NOSSA FRÁGIL CONDIÇÃO HUMANA
}

\section{ABOUT MONSTERS AND IMAGINARY BEINGS MOACYR SCLIAR'S WORK: OUR FRAGILE HUMAN CONDITION}

Lyslei Nascimento*

Desde a coleção de contos O carnaval dos animais, publicada em 1968 (SCLIAR, 1998), com a qual ganha o Prêmio Academia Mineira de Letras, Moacyr Scliar faz habitar em sua obra monstros e seres imaginários que parecem apontar para a ficção como um lugar propício para que irrompa o maravilhoso e o extraordinário. No entanto, híbridos, lendários ou estranhos, alguns personagens parecem, num nível simbólico ou metafórico, deixar vislumbrar alertas, sempre necessários, de que precisamos preservar o que ainda resta de humano em nós. O estranho e o dissonante, em Scliar, advertem-nos, assim, para que não nos vejamos, a nós e ao próximo, como uma massa amorfa, robotizada, acrítica e, muitas vezes, transformada em pedra e sal.

Nesse primeiro livro, um bestiário de animais como leões, ursas, coelhos, mas também super-heróis aposentados e desmemoriados, como Capitão Marvel, Homem Invisível, Príncipe Submarino e Zorro, ou transgressores, como a dissimulada canibal, junto a medusas, centauros, golems e andróginos, não sem ironia, constituem-se a partir das características que Italo Calvino apontaria como valores de uma literatura que irá sobreviver ao milênio

\footnotetext{
* É graduada em Letras para UFMG, em 1991. Doutora em Literatura Comparada pela mesma universidade, em 2001. Fez pós-doutorado em Ciências Sociais na Universidade de Buenos Aires, em 2004 e pós-doutorado em Letras pela USP, em 2016.
} 
Cad. Líng. Lit. Hebr., n. 15, p. 3-9, 2017

(CALVINO, 1990). Nesse sentido, o que é múltiplo, leve, visível, rápido, exato e conciso é também resistente e autorreflexivo.

No prólogo a O livro dos seres imaginários, Jorge Luis Borges (1989) afirma que o nome desse livro justificaria a inclusão, em um rol de seres imaginários, de Hamlet, do ponto, da linha, da superfície, do hipercubo e de todas as palavras genéricas, além de cada um de nós e de Deus. O leitor deverá, portanto, estar atento para a metalinguagem que está impregnada nessa lista, porque ela corrompe e desconstrói categorias, ao arrolar elementos tão díspares, todos alinhavados no espaço comum da literatura.

Levando a lista ao absurdo, Borges (1989) espera chamar atenção para a diversidade, mas também para o que é heterogêneo e heterodoxo, afinal. Hamlet, como um personagem de Shakespeare, caberia, nesse rol, todos os personagens de ficção. O ponto, a linha, a superfície e o hipercubo elencam, por metonímia, as relações entre a geometria, o tempo e o espaço com a matemática e a física; dentro e fora da lógica cartesiana, essa lista também indica a multiplicidade da narrativa. Além disso, não podemos esquecer que tanto o ponto quanto a linha evocam a arcaica etimologia latina da palavra texto: construir, tecer, cujo particípio passado textus também era usado como substantivo e significava 'maneira de tecer', ou 'coisa tecida', e ainda mais tarde, 'estrutura'.

A partir do século XIV, a evolução semântica da palavra atingiu o sentido de “tecelagem ou estruturação de palavras" ou ainda de "composição literária". Borges (1989) afirma, paradoxalmente, que esse suposto livro de seres imaginários deveria conter, ainda, todas as palavras genéricas de catálogos, dicionários, línguas, idiomas. Ora, se todas as palavras devem ser entendidas como seres imaginários, Borges não estaria apontando para o mundo como um espaço da e de linguagem? 
NASCIMENTO, Lyslei. Sobre monstros e seres imaginários na obra de Moacyr Scliar

O prólogo do livro borgiano contém uma irônica instrução de leitura que pode iluminar, nesse momento, nosso olhar sobre a imprescindível obra de Scliar. Como os verbetes de Borges, os seres imaginários de Scliar configuram-se como uma enciclopédia de monstruosidades, jogos de espelhos, de combinações e novos reagrupamentos que potencializam a memória e a narrativa.

Para além das narrativas mitológicas rígidas, que podem pretender perpetuar o mesmo, os estranhos personagens de Scliar fazem proliferar a diversidade e a coexistência para além do que se convencionou chamar de tolerância. Com eles, a monstruosidade abre-se para um sismo no olhar homogeneizante e vazio. Cada personagem, em sua irredutível dessemelhança, delineia as ambiguidades, a natureza híbrida e a crise de categorias. A recusa em fazer parte da ordem classificatória das coisas vale para os monstros em geral, mas em Scliar, essa recusa é paradigmática.

Regina Zilberman, a propósito do romance $O$ centauro no jardim, publicado em 1997, afirma:

a natureza do centauro passa do protagonista ao todo da obra, evidenciando sua natureza; e assegura que, se a sociedade é a zona onde o homem negocia sua espontaneidade e autonomia, a literatura é o setor onde estas podem ser restauradas, à medida em que se efetiva uma crítica e a exposição de uma utopia mágica. (ZILBERMAN, 1997)

Essa "utopia mágica" passa, certamente, pela literatura como o lugar do insólito que ali se apresenta de forma a abalar a leitura monolítica da tradição e da própria natureza da literatura.

Desde a primeira frase do romance, o leitor está diante de um sentimento inquietante que revela tanto o desejo de assimilação e o afã da normalidade quanto a sua impossibilidade: “Agora é sem galope. Agora está tudo bem. Somos, agora, iguais a todos. Já não chamamos a 
Cad. Líng. Lit. Hebr., n. 15, p. 3-9, 2017

atenção de ninguém”, afirma o narrador, "passou a época em que éramos considerados esquisitos" (SCLIAR, 1997, p. 10), acredita o ex-centauro.

Diante de um tempo que exige o sacrifício de peculiaridades e características individuais para que se possa ser aceito e sobreviver numa sociedade cada vez mais impositiva e niveladora, ostentar a diferença é, pois, provocar estranheza e sofrer isolamento. O centauro, na sua dupla natureza, lembra que em meio ao desejo de semelhança e de igualdade jaz um sujeito assujeitado. Nesse sentido, ele caminha, em ritmo galopante, para sua destruição. O desejo de transformação do corpo fantástico em um ser humano comum acaba por gerar outra monstruosidade, de caráter mais íntimo e privado (NASCIMENTO, 2009).

Guedali, o centauro judeu, submete-se a uma série de cirurgias plásticas para perder sua aparência de centauro. Seu corpo, meio humano, meio cavalo, é remodelado por uma medicina que, apesar de apresentar-se entre o charlatanismo e a vanguarda científica, mostrase muito eficiente em produzir o efeito desejado: a impressão material da normalidade. Sob a pele, no entanto, esconde-se a natureza agônica do centauro.

O fato de eliminar as patas equinas, os cascos e o couro cavalar e transformar-se em um ser humano comum, lembra Regina Igel, é trocar os galopes da liberdade pelos passos miúdos da mediocridade (IGEL, 1997). A contrapelo dessa tentativa de mascaramento, a cena da circuncisão, paradoxalmente arcaica, revela, em sua perenidade simbólica, para além de todas as práticas políticas e autoritárias de apagamento da memória e de desejo de assimilação, uma inscrição do indivíduo a partir de uma "impressão", no sentido do que é deixado para significar e o que é impresso, uma ferida, uma cicatriz, sobre a pele, sob a pele (DERRIDA, 2001). 
A natureza híbrida dos monstros, ou dos seres imaginários, segundo Jeffrey Cohen, perturba e aterroriza porque seus corpos incoerentes resistem à estruturação sintagmática e, apesar de habitar nossa ilusória unicidade, o estranho ou monstruoso é um corpo cultural, que pode deixar-se inscrever por qualquer tipo de alteridade e, sendo assim, a diferença monstruosa pode ser cultural, política, social, étnica, econômica e/ou sexual (COHEN, 2000).

Outro perturbador personagem de Scliar que traz à tona nossa frágil condição humana é o pequeno Golem de Cenas da vida minúscula, de 1991 (SCLIAR, 2003). Da Bíblia à Amazônia, passando pela Europa do século XVI, a magia, a alquimia, a astrologia, a cabala e a ciência põem em cena a reescrita do episódio da criação do homem, gerando um desejo de emulação, não sem soberba, do ato divino. Assim, como num jogo de espelhos que reduplica as imagens, ora plasmando-as, quase como um carimbo à moda da impressão, ora deformando os seres e objetos que recria, o leitor vai acompanhando a narrativa em primeira pessoa de um ser imaginário, compósito ou enciclopédico, que ostentaria tudo o que se sabe sobre a criação:

Não é pouco o que hoje sei, portanto começo com Kafka, que resume tudo nesse aforismo: "Duas possibilidades: infinitamente pequeno ou fazer-se infinitamente pequeno. A primeira possibilidade é perfeição, portanto, inação; a segunda é o começo, portanto ação." Franz Kafka - sei, sim, quem é. Porque não pouco o que hoje sei. (SCLIAR, 2003, p. 5)

A partir dessa visão quase panóptica, o mínimo Golem, o estranho ser de Scliar, dá testemunho de um saber que não se alicerça nem no discurso religioso, como se poderia esperar, nem no texto científico, também previsível. O saber está, imaginariamente, em Franz Kafka, construtor de um dos seres mais visualmente sugestivos da literatura: o inseto no qual se transformou, um dia, o caixeiro-viajante Gregor Samsa, que abandona todos os seus desejos para tentar pagar dívidas que não são suas (KAFKA, 2001).

Como uma rede, a obra de Scliar vai sofrendo e provocando metamorfoses, deixando-se entremear ou impregnar de outros textos, como uma teia em que habita, célere, um ser 
Cad. Líng. Lit. Hebr., n. 15, p. 3-9, 2017

imaginário, como uma aranha, tão afeito à construção de casas-armadilha, o escritor, arquiteto de labirintos.

O mínimo Golem de Scliar, em contraposição ao gigante de barro da tradição judaica, conclui a sua história com uma constatação que é, também, uma afirmação da literatura:

Quem sabe dos segredos que se ocultam no interior de certas máquinas, senão o Baixinho? Aquilo que seria uma incógnita para o Rei Salomão, aquilo que desafiaria a magia de Habacuc, ele tira de letra - e esta letra não figura em nenhum Livro das Origens. Aqui, Del Rey. Mas aqui, também, Baixinho. Breve, como o seu novo nome. Não é pouco o que hoje sei, digo, e esta verdade me faz sorrir, se não feliz, ao menos pacificado: não é pouco o que hoje sei. (SCLIAR, 2003, p. 247)

A literatura em Scliar, como uma máquina de narrar, provê alguns segredos que só um leitor disposto a errar pode entrever. Nessa maquinaria, como poderia afiançar Calvino, a ficção não é um objeto inalcançável de uma busca sem fim. Ao contrário, estrategicamente, em mínima escala, como o apelido do personagem, Baixinho, o que poderia ter um peso esmagador é um rir-se de si mesmo, dissolvendo, com essa atitude, o peso do mundo. Daí que, uma outra letra, outras letras, recriam o mundo por intermédio da escrita e da leitura. $\mathrm{O}$ texto de Scliar, assim, estrutura-se sutil e breve sobre pequeninos pontos ou nós de uma rede. Essa leveza evita, pois, que o peso dos tempos nos esmague.

No universo infinito da literatura, adverte-nos Calvino, quando parece que estamos para sempre condenados ao peso do mundo, num imenso e incomensurável cemitério de automóveis, podemos mudar o ponto de observação (CALVINO, 1990, p. 24). Nesse sentido, as grandes alturas e o saber monolítico são substituídos por cenas da vida minúscula, novos, antigos ou arcaicos caminhos, monstros e seres imaginários que podem mudar, de repente, nossa posição no mundo.

Portanto, mesmo no interior de grandes máquinas, engrenagem na qual estamos fatalmente presos, possa a leveza do anão no televisor; do Baixinho, o mínimo Golem; ou do 
NASCIMENTO, Lyslei. Sobre monstros e seres imaginários na obra de Moacyr Scliar

centauro circuncidado (FREITAS, 2012) e de outros seres imaginários da obra de Moacyr

Scliar mudar sempre nosso olhar e nos acompanhar na luta contra o esquecimento, a morte.

\section{Bibliografia}

BORGES, J. L. O livro dos seres imaginários. Tradução Carmen Vera Cirne Lima. São Paulo: Globo, 1989.

CALVINO, I. Seis propostas para o próximo milênio. Tradução Ivo Barroso. São Paulo: Companhia das Letras, 1990.

COHEN, J. J. A cultura dos monstros: sete teses. In: SILVA, T. T. (Org.). Pedagogia dos monstros: os prazeres e os perigos da confusão de fronteiras. Belo Horizonte: Autêntica, 2000. p. 23-60.

DERRIDA, J.; FREUD, S. Mal de arquivo: uma impressão. Tradução Claudia de Moraes Rego. Rio de Janeiro: Relume Dumará, 2001.

FREITAS, M. V. A leveza do centauro. Arquivo Maaravi: Revista Digital de Estudos Judaicos da UFMG. Belo Horizonte, v. 6, n. 11, out. 2012. Disponível em: $<$ https://goo.gl/5wvoAh>. Acesso em: 21 mar. 2017.

IGEL, R. Imigrantes judeus, escritores brasileiros. São Paulo: Perspectiva, 1997.

KAFKA, F. A metamorfose. Tradução Marcelo Backes. Porto Alegre: L\&PM, 2001.

NASCIMENTO, L. Da circuncisão de um centauro. Arquivo Maaravi: Revista Digital de Estudos Judaicos da UFMG. Belo Horizonte, v. 6, n. 11, out. 2012. Disponível em: $<$ https://goo.gl/nFdHXA>. Acesso em: 12 mar. 2017.

SCLIAR, M. O centauro no jardim. Porto Alegre: L\&PM, 1997. p. 10.

. O carnaval dos animais. Rio de Janeiro: Ediouro, 1998.

. Cenas da vida minúscula. Porto Alegre: L\&PM, 2003.

ZILBERMAN, R. Contracapa. In: SCLIAR, M. O centauro no jardim. Porto Alegre: L\&PM, 1997. 